J. Lake Sci.(湖泊科学), 2020, 32(2): 370-379

DOI 10. 18307/2020. 0207

(c) 2020 by Journal of Lake Sciences

\title{
引水结构变化对天津于桥水库磷滞留的影响分析与生态水量估算”
}

\author{
张 晨 ${ }^{1 * *}$, 宋迪迪 ${ }^{1}$, 廉铁辉 ${ }^{2}$ \\ ( 1 : 天津大学水利工程仿真与安全国家重点实验室,天津 300350) \\ (2:天津市引滦工程于桥水库管理处,天津 301900)
}

\begin{abstract}
摘 要: 2014 年南水北调中线一期工程通水后, 天津市的水源结构发生变化, 由单一㴒河水源变为双水源. 引水结构变 化导致于桥水库人库水量变化, 从而影响水库的总磷 (TP) 滞留. 一般认为, 人库总磷负荷随人库水量减少而降低, 且水 力停留时间越长, 将越有利于总磷滞留, 从而水库 TP 浓度降低. 但根据统计数据发现, 南水北调通水后于桥水库人库水 量降低, TP 负荷反而升高, 水库 TP 浓度升高. 何种 TP 滞留机制造成了这样的结果? 本文通过分析 2001-2018 年间人 库水量 $\left(W_{\mathrm{IN}}\right)$ 、入库总磷负荷 $\left(T P L_{\mathrm{IN}}\right)$ 在南水北调通水前后的变化规律, 采用 Vollenweider 模型推求水库 TP 浓度和磷滞 留量 $\left(R_{\mathrm{P}}\right)$, 探讨水力停留时间 $(\tau)$ 对库区总磷滞留量的影响机制, 并估算双水源新情势下控制于桥水库磷滞留量的生 态水量. 结果表明: $T P L_{\mathrm{IN}}$ 随 $W_{\mathrm{IN}}$ 呈先降低后升高趋势; 引水期 $\tau$ 与 $R_{\mathrm{P}}$ 之间存在显著的正相关关系, 随着 $\tau$ 增加, 正相关性 下降, 但同时考虑非引水期和引水期 $\tau$ 时, $R_{\mathrm{P}}$ 受较小的 $T P L_{\mathrm{IN}}$ 影响与 $\tau$ 呈负相关. 根据上述关系推算, 在双水源新情势 下, 为保持于桥水库中贫营养状态, 控制磷滞留量为南水北调通水前水平, 建议每年人库生态水量大于 5 亿 $\mathrm{m}^{3}$, 出库生 态水量约为人库水量的 $80 \%$, 配合新建前置库工程运行将有效保障水库水源功能.
\end{abstract}

关键词: 总磷负荷; 水力停留时间; 磷滞留; Vollenweider 模型; 生态水量;于桥水库

\section{The influences of the water diversion structure change on total phosphorus retention and implication for ecological flows in Yuqiao Reservoir, Tianjin*}

\author{
ZHANG Chen ${ }^{1 * *}$, SONG Didi ${ }^{1} \&$ LIAN Tiehui ${ }^{2}$ \\ (1: State Key Laboratory of Hydraulic Engineering Simulation and Safety, Tianjin University, Tianjin 300350, P.R. China) \\ (2: Yuqiao Reservoir Administrative Bureau of Luan River-Tianjin Water Diversion Project, Tianjin 301900, P.R. China)
}

Abstract: After supplying water to Tianjin City by the South-to-North Water Diversion Project (SNWD) in 2014 , the water source
has changed from a solely source of Luanhe to two sources. The new water diversion structure changed the amount of water into the
Yuqiao Reservoir, which affected the total phosphorus ( TP) retention of the reservoir. It is generally agreed that the TP loadings
decrease with the decreasing of the inflow water of the reservoir. The longer hydraulic retention time ( $\tau$ ), the more favorable to TP
retention, and thus the TP concentration of the reservoir decreases. However, we found that the TP loadings increased with the de-
creased inflow water when water supplied by SNWD, and the reservoir TP concentration also increased. What is the TP retention
mechanism causing such a result? Based on the observed inflow water ( $W_{\mathrm{IN}}$ ) and the TP loadings ( $\left.T P L_{\mathrm{IN}}\right)$ from 2001 to 2018 , the
reservoir TP concentration and TP retention ( $R_{\mathrm{P}}$ ) were estimated by the Vollenweider model. Consequently, we estimated the eco-
logical flows by controlling the amount of $R_{\mathrm{P}}$ at the level before the SNWD. The results showed that $T P L_{\mathrm{IN}}$ was non-monotonous re-
spond to $W_{\mathrm{IN}}$. There was a significantly positive relationship between $\tau$ and $R_{\mathrm{P}}$ during water diversion period. Interestingly, this pos-
itive correlation decreased with the increasing of $\tau$. However, the $R_{\mathrm{P}}$ is negatively related to $\tau$ due to lower $T P L_{\mathrm{IN}}$ when considering
both non-water diversion and water diversion period. Undergoing the new situation of two water sources in Tianjin City, it's feasible
for maintaining oligotrophic or mesotrophic state of Yuqiao Reservoir. To control phosphorus retention, we suggest that the ecologi-
cal flow into the reservoir is more than 500 million $\mathrm{m}^{3}$ every year, and the ecological outflow of the reservoir can be about $80 \%$ of

* 2019-09-04 收稿; 2019-10-11 收修改稿.

国家重点基础研发计划项目(2018YFC0407203) 和国家自然科学基金项目(51679160)联合资助.

** 通信作者; E-mail: emil@ tju.edu.cn. 
the inflow.

Keywords: Total phosphorus loading; hydraulic retention time; phosphorus retention; Vollenweider model; ecological flow; Yuqiao Reservoir

引调水工程是解决水资源时空分布不均、缓解资源性缺水问题、优化水资源配置的重要举措 ${ }^{[1]}$. 在跨流 域引水系统中,调蓄湖库一定程度上能够缓解水资源供需矛盾,但其供水水质也会受到引调水、当地地表水 等不同来水的影响 ${ }^{[2]}$. 总磷 (TP) 是调蓄湖库水质优劣的显著性指示指标 ${ }^{[3-4]}$, 与湖库水生态之间有着密切 联系, 弄清哪些因素影响湖库磷滞留量是保障供水水质安全的前提. 前人研究成果分析了外部营养负荷、单 位面积磷负荷率、单位面积水力负荷、平均湖深、水力停留时间、冲刷率等一系列因素对磷滞留的影响 ${ }^{[5-7]}$. Vollenweider 模型 ${ }^{[8-10]}$ 是众多学者针对这一问题得到的典型成果, 该模型基于湖泊总磷负荷质量平衡原理, 提供了一种基于湖库形态测量和水力数据预测湖泊水体磷滞留的工具. 模型指出外部 TP 负荷、水力停留时 间、冲刷率是磷滞留的重要影响因子 ${ }^{[3]}$. 后续研究证实了该观点, 外部营养负荷决定了湖泊的总体水质,但 沉积物对磷的内部循环起着核心作用 ${ }^{[1-12]}$. 水力停留时间通过流动的快慢影响营养物和有机物的供应和流 失, 冲刷率为水力停留时间的倒数 ${ }^{[13]}$, 它们影响湖库中 TP 浓度 ${ }^{[3,14]}$. 一般认为, 湖泊的水力停留时间越长、 冲刷率越小, 将有更多的磷滞留, 湖水 TP 浓度越低 ${ }^{[15-16]}$. 反之, 在一些调蓄水库中, 水力停留时间较短 (冲刷 率较大), 磷往往未参与内部循环便被带出. 但是, $\mathrm{Wu}$ 等 ${ }^{\left[{ }^{[1]}\right.}$ 对太湖、巢湖和鄱阳湖研究发现, 预测 $\mathrm{TP}$ 浓度随 着水力停留时间的增加 (冲刷率的减少) 而升高, 这是因为沉积物中的磷还原释放到水中导致 TP 浓度升高.

“引㴒人津” 工程是我国早期建成的大型跨流域调水工程, 解决了天津城市生活及工业用水需求. 南水 北调通水前, 于桥水库是天津市唯一饮用水水源地,也是 “引滦人津” 工程的重要调蓄水库, 年均受纳滦河水 系引水 5.4 亿 $\mathrm{m}^{3}$ ( $2001-2014$ 年). 2014 年底, 南水北调中线一期工程通水后, 天津市的水源结构发生变化, 主要饮用水源从滦河水变为长江水 (引江水不调人于桥水库). 引水结构的变化导致外调滦河水的需求发生 改变,进而影响于桥水库受纳引水量. 对于桥水库而言,引水量的变化影响外部营养负荷的改变, 水库运行 方式和出人库流量的变化也影响水库 TP 浓度. 已有研究表明, 于桥水库处于中贫营养水平、沉水植物为主 的清水状态, 但沉水植物物种单一, 清水稳态易发生转变 (破坏) ${ }^{[18-19]}$. 同时, 根据监测结果, 水库 TP 浓度自 2013 年之后有升高趋势, 若一旦超过清水转换阈值将突变为藻型浊水状态 ${ }^{[20]}$, 修复富营养化将十分困难. 最新成果表明,城市的用水需求、引水量、土地利用和气候变化均将深刻影响于桥水库的水质状况 ${ }^{[21]}$. 综 上,在关注于桥水库 TP 浓度时, 弄清引水结构变化引起的人库水量、外部 TP 负荷、水力停留时间改变对磷 滞留的影响机制是重要科学问题.

本研究基于于桥水库 2001-2018 年实测资料,利用 Vollenweider 模型计算 TP 浓度动态过程,分析人库 水量、外部 TP 负荷、水力停留时间三个因素对南水北调通水前后水库磷滞留量的影响,并进一步估算双水 源新情势下的生态水量, 为保持于桥水库中贫营养状态提供科学的运行管理建议.

\section{1 材料与方法}

\section{1 研究区域概况}

于桥水库 $\left(40^{\circ} 00^{\prime} \sim 40^{\circ} 04^{\prime} \mathrm{N}, 117^{\circ} 26^{\prime} \sim 117^{\circ} 37^{\prime} \mathrm{E}\right)$ 位于天津市蓟州区城东 $4 \mathrm{~km}$ 处, 自 1983 年“引滦人 津” 输水工程通水后, 是天津市人民生活饮用及工农业用水的主要水源地, 也是 “引㴒人津” 输水工程的重要 调蓄水库 ${ }^{[22]}$. 控制流域面积 $2060 \mathrm{~km}^{2}$, 占整个州河流域面积的 $96 \%$, 图 1 所示. 最大回水长东西约 $30 \mathrm{~km}$, 南 北宽 $8 \mathrm{~km}$, 最大淹没面积 $250 \mathrm{~km}^{2}$, 正常蓄水位 $21.16 \mathrm{~m}$ 时淹没面积 $86.8 \mathrm{~km}^{2[23]}$, 汛限水位 $19.87 \mathrm{~m}$, 死水位 $15 \mathrm{~m}$. 浅水库, 平均水深 $4.6 \mathrm{~m}$, 总库容 15.59 亿 $\mathrm{m}^{3}$. 水库控制流域属于温带大陆性季风性半湿润气候, 境内 雨量充沛,多年平均降水量为 $748.5 \mathrm{~mm}$, 主要集中在 6-9 月, 水库多年平均径流量 5.06 亿 $\mathrm{m}^{3[24-25]}$. 于桥水 库是一座典型的山谷与平原过渡的水库 ${ }^{[26]}$, 库区南岸地势陡峭受原河道深泓控制水深大, 北岸地势则相对 平坦水深浅 ${ }^{[27]}$. 由沙河、淋河、黎河三大支流汇合而成, 其中黎河为引滦输水通道, 与沙河汇流果河后随果 河汇人于桥水库.

\section{2 数据来源与处理}

1.2.1 水量 黎河逐日总水量来源于前毛庄监测站,为黎河自产水量与引水量之和, 2001-2018 年平均径流 


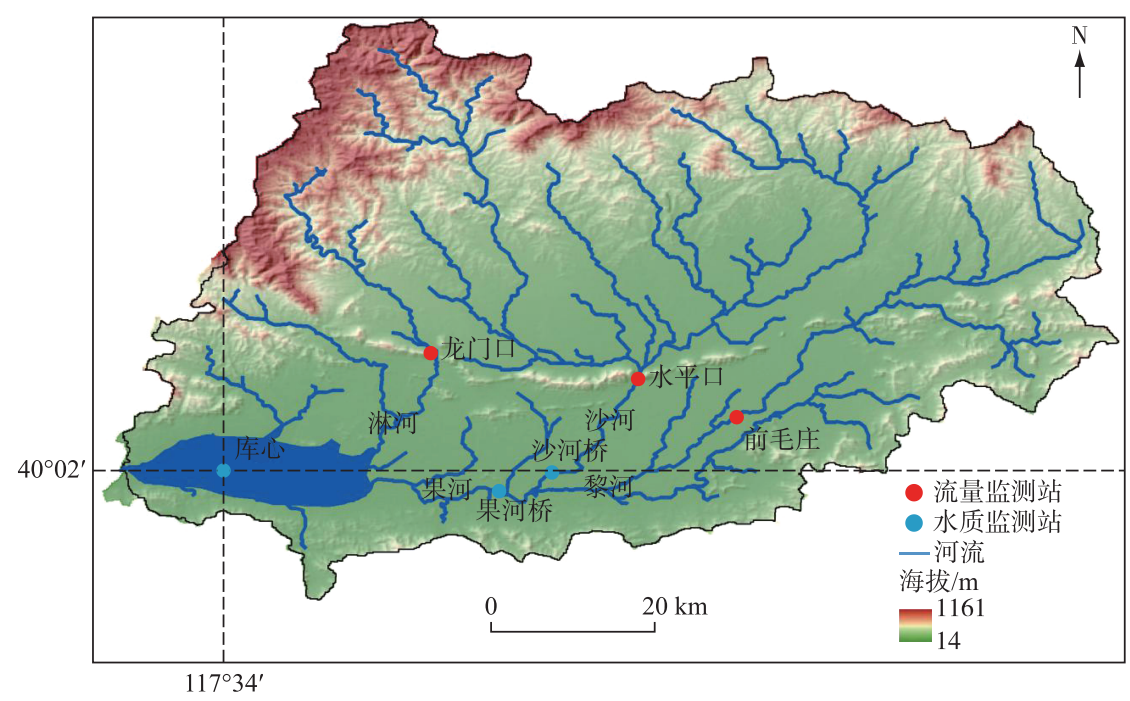

图 1 于桥水库流域及水文监测站

Fig.1 Yuqiao Reservoir basin and monitoring stations

量为 5.65 亿 $\mathrm{m}^{3}$, 引水量为 4.79 亿 $\mathrm{m}^{3}$. 沙河逐日流量来源于水平口监测站, 为自产水量, 平均径流量为 0.95 亿 $\mathrm{m}^{3}$; 淋河逐日水量来源于龙门口 (2012-2018 年为淋河桥站) 监测站, 平均径流量 0.16 亿 $\mathrm{m}^{3}$, 由于人库水 量远小于黎河和沙河, 且年内常处于断流状态, 故本研究中忽略淋河. 果河水量即人库水量 $W_{\mathrm{IN}}$, 为黎河与沙 河水量之和,多年平均径流量为 6.60 亿 $\mathrm{m}^{3}$.

1.2.2 TP 负荷 各监测点 TP 浓度逐月数据源自水库管理部门. 沙河水质取样点位于沙河桥, 2001-2018 年 $\mathrm{TP}$ 浓度平均值 $89.5 \mu \mathrm{g} / \mathrm{L}$; 人库 TP 浓度 $T P_{\mathrm{IN}}$ 取样点位于沙河、黎河汇流后的果河桥, 平均浓度 $201 \mu \mathrm{g} / \mathrm{L}$; 黎 河 $\mathrm{TP}$ 浓度根据磷质量平衡反算得出; 库区 $\mathrm{TP}$ 浓度 $T P_{L}$ 由 $T P_{I N}$ 计算得到, 详见下文公式 $(3)$, 年均值 36.8 $\mu \mathrm{g} / \mathrm{L}$. 沙河、人库、黎河、出库各点 TP 负荷由水量与浓度计算得到.

1.2.3 数据处理 沙河、黎河 2013-2018 非汛期部分月份缺失的水量数据由皮尔逊 III 型曲线插值确定, 再 根据水量平衡, 结合已有的引水数据对不合理插值结果进行修正, 修正后月数据累加后得到的年水量与水 资源公报中年水量相对误差为 $4 \%$.

\subsection{Vollenweider 模型}

Vollenweider 模型用于预测已知营养负荷输人和水力停留时间的湖泊营养浓度, 已被广泛用于估算湖泊 和水库中的 TP 浓度, 数学表达式为 ${ }^{[7]}$ :

$$
T P_{\mathrm{L}}=\frac{L}{H\left(S_{\mathrm{r}}+\sigma\right)}
$$

式中, $T P_{\mathrm{L}}$ 代表水库 $\mathrm{TP}$ 浓度 (库心测点) , $\mu \mathrm{g} / \mathrm{L} ; L$ 表示总磷的单位面积负荷率, 单位 $\mathrm{mg} /\left(\mathrm{m}^{2} \cdot \mathrm{s}\right)$, 由人库总磷 负荷 $T P L_{\mathrm{IN}}$ 除以库区面积 $A$ 得到, $\mathrm{t} / \mathrm{a}$; 其中, $T P L_{\mathrm{IN}}$ 等于人库流量 $Q$ 与人库总磷浓度 $T P_{\mathrm{IN}}$ 的乘积; $H$ 为平均水 深, 单位 $\mathrm{m} ; S_{\mathrm{r}}$ 为冲刷率, $\mathrm{a}^{-1}$, 等于人库流量 $Q$ 比库容 $V ; \sigma$ 为沉降率, 代表湖泊磷流失的一阶速率系数, $\mathrm{a}^{-1}$. 以人库总磷浓度表示, 式 (1) 化为:

$$
T P_{\mathrm{L}}=T P_{\mathrm{IN}} /(1+\sigma \tau)
$$

式中, $\tau$ 为水力停留时间, 等于 $V / Q$, a ; 根据 Brett 和 Benjamin ${ }^{[3]}$ 研究成果, 本文假设 $\sigma=a \tau^{b}$, 其中 $a$ 代表湖 内磷衰减的无量纲参数, $b$ 代表通过水文冲刷输出磷的无量纲参数, 两个参数由式 (3) 和实测数据统计回归 求得 (见下文).

$$
T P_{\mathrm{L}}=T P_{\mathrm{IN}} /\left(1+a \tau^{b+1}\right)
$$




\section{4 库区总磷滞留量}

营养物质进人水体受生物、物理及化学过程的影响而截留或通过形态转化损失, 从而影响物质向下游 的输送通量,这些过程广义上被称为 “滞留作用” ${ }^{[28-29]}$. 沉积物中磷的滞留量常由以下质量平衡的差值计算 得出: 磷滞留量 $=$ 磷总负荷 - 磷损失量 - 磷转换量 ${ }^{[30]}$. 由于磷损失和磷转换均发生在水库内部, 大部分成为内 部负荷, 结合 Vollenweider 模型, 故本文将磷损失量及转换量一同视作滞留量, 并用 $R_{\mathrm{P}}$ 表示, 定义为:

$$
R_{\mathrm{P}}=T P L_{\mathrm{IN}}-T P L_{\mathrm{OUT}}
$$

式中, $T P L_{\mathrm{OUT}}$ 表示出库 $\mathrm{TP}$ 负荷 $(\mathrm{t} / \mathrm{a})$. 在湖库混合良好, 处于稳定状态的假设条件下, 出库 $\mathrm{TP}$ 浓度 $T P_{\mathrm{OUT}}$ 等 于 $T P_{\mathrm{L}}{ }^{[10]}, T P L_{\text {OUT }}$ 计算为出库流量与式 (3) 算得的库心 $\mathrm{TP}$ 浓度 $T P_{\mathrm{L}}$ 的乘积. 滞留率为 $R_{\mathrm{P}}$ 与 $T P L_{\mathrm{IN}}$ 的比 值 $(\%)$.

\section{2 结果分析}

\section{1 南水北调通水前后 $W_{\mathrm{IN}}$ 和 TP 负荷变化规律}

2.1.1 入库水量 $W_{\mathrm{IN}}$ 变化 从 $W_{\mathrm{IN}}$ 年际变化来看, 由图 2(a) 可知, 2001-2014 年, 南水北调通水前, $W_{\mathrm{IN}}$ 年均值 6.88 亿 $\mathrm{m}^{3}$, 其中流域自产水量 1.51 亿 $\mathrm{m}^{3}$, 引水量 5.37 亿 $\mathrm{m}^{3} .2001-2005$ 年 $W_{\mathrm{IN}}$ 相对较少, 2006- 2013 年略 有增加, 但波动幅度较小, 直至 2014 年引水量大幅提高, $W_{\mathrm{IN}}$ 达到峰值 11.08 亿 $\mathrm{m}^{3} .2014$ 年南水北调通水后, $W_{\mathrm{IN}}$ 年均值为 5.16 亿 $\mathrm{m}^{3}$, 其中自产水量 2.39 亿 $\mathrm{m}^{3}$, 引水量 2.77 亿 $\mathrm{m}^{3}$, 且 2016 年 $W_{\mathrm{IN}}$ 为历年最低, 仅有 3.04 亿 $\mathrm{m}^{3}$. 对比南水北调通水前后, 年均 $W_{\mathrm{IN}}$ 减少了 1.72 亿 $\mathrm{m}^{3}$, 其中, 引水量减少 2.6 亿 $\mathrm{m}^{3}$ 是导致 $W_{\mathrm{IN}}$ 大幅减少 的主要原因. 由此表明,引水结构变化致使于桥水库调水需求发生改变, 人库水量剧减.
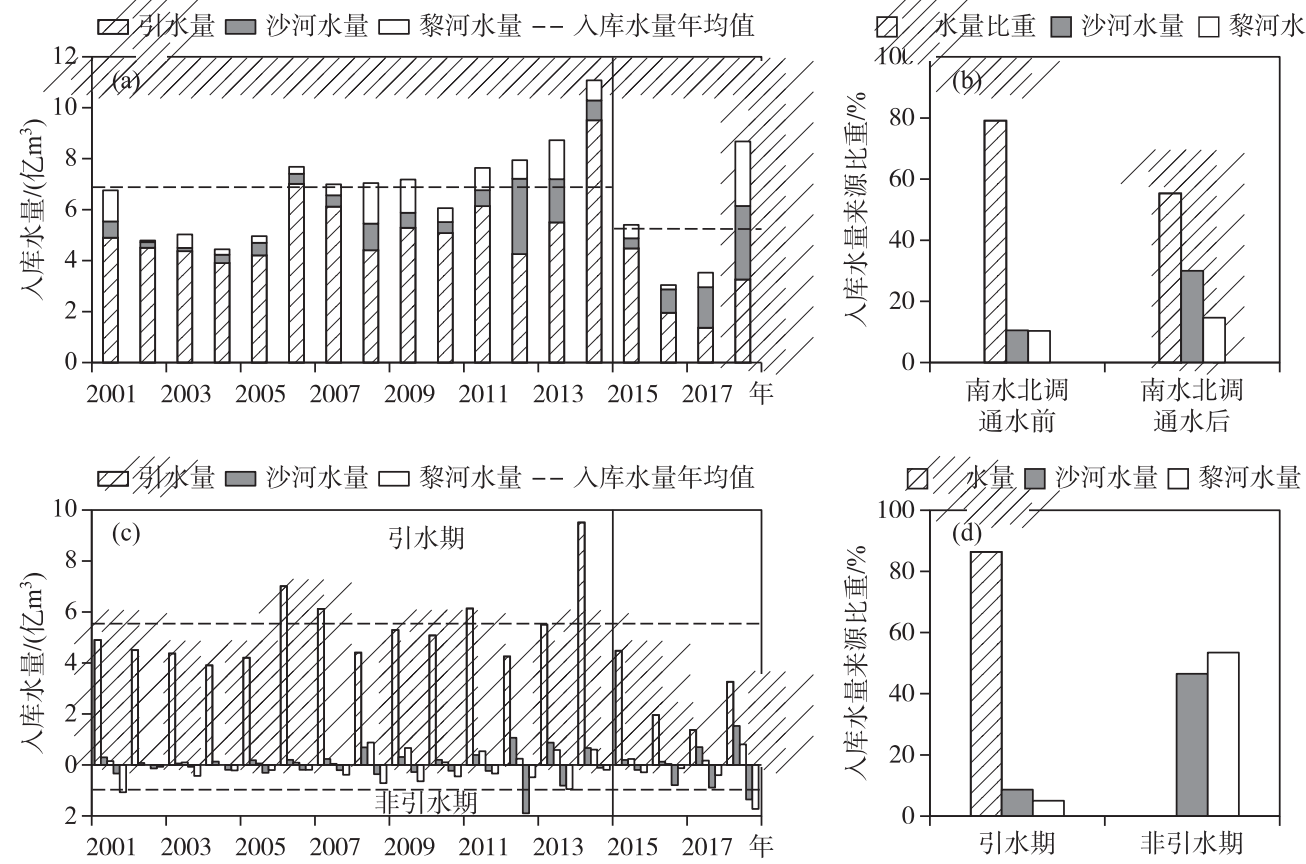

图 $22001-2018$ 年于桥水库人库水量

Fig. 2 Inflow volume flow into Yuqiao Reservoir during 2001-2018

$W_{\mathrm{IN}}$ 来源比例方面, 如图 2b 所示, 2001-2014 年, 南水北调通水前, 沙河、黎河自产水分别占总水量的 $11 \%$ 和 $10 \%$,引水比重较大,约为 $79 \%$. 南水北调通水后, 沙河、黎河自产水分别占总水量的 $29 \%$ 和 $15 \%$, 而 引水比重显著下降为 56\%. 南水北调通水前后, 沙河、黎河自产水比重分别提高 $18 \%$ 和 5\%, 引水比重显著下 降 $23 \%$. 水量来源方面发生变化, 沙河自产水对水库来水的贡献增加. 
进一步分析引水期和非引水期 $W_{\mathrm{IN}}$ 变化, 如图 2(c) 所示, 引水期 $W_{\mathrm{IN}}$ 年均值为 5.53 亿 $\mathrm{m}^{3}$, 引水量 4.79 亿 $\mathrm{m}^{3}$, 沙河水量 0.44 亿 $\mathrm{m}^{3}$, 黎河水量 0.30 亿 $\mathrm{m}^{3}$. 其中, 2004 年水量略少. 非引水期, $W_{\mathrm{IN}}$ 年均值仅为 0.97 亿 $\mathrm{m}^{3}$, 不足引水期 $1 / 5$, 沙河水量 0.48 亿 $\mathrm{m}^{3}$, 黎河水量 0.49 亿 $\mathrm{m}^{3}$, 二者持平. 值得注意的是, 2012 年沙河水量 远超黎河, 为历年最大, 达到 1.89 亿 $\mathrm{m}^{3}$. 对比引水期与非引水期, 沙河水量始终在 0.45 亿 $\mathrm{m}^{3}$ 左右. 非引水期 黎河来水平均占比 $51 \%$, 沙河 $49 \%$; 引水期和非引水期黎河自产水和沙河比重基本持平 (图 $2 \mathrm{~d}$ ). 人库自产 水量方面,引水期与非引水期沙河自产水量无显著变化,而黎河非引水期自产水量增加了 $63 \%$.

2.1.2 入库总磷负荷 $T P L_{\mathrm{IN}}$ 变化 由图 3( a) 可知, 南水北调通水前, $T P L_{\mathrm{IN}}$ 年际变化相对平缓, 整体水平较低, 年均值为 111.42 t/a. 2004 年出现第一个小高峰达到 $154.70 \mathrm{t} / \mathrm{a}, 2008$ 年降到历年最低 $42.65 \mathrm{t} / \mathrm{a}$ 后便逐年上 升, 并于 2014 年达到最高峰 $249.61 \mathrm{t} / \mathrm{a}$. 南水北调通水后, 波动较为剧烈, 年均值上升至 $163.26 \mathrm{t} / \mathrm{a}$, 较通水 前增加了 $51.84 \mathrm{t} / \mathrm{a}$. 其中 2016 年达到历年最高 $254.85 \mathrm{t} / \mathrm{a}, 2017$ 年又骤降为 $55.91 \mathrm{t} / \mathrm{a}$. 引水 $\mathrm{TP}$ 负荷与 $T P L_{\mathrm{IN}}$ 类似, 于 2008、2014 年分别达到南水北调通水前最小值和最大值, 2016 年达到通水后峰值, 2017 年又大幅降 低. 由此可见,引水 TP 负荷是影响 $T P L_{\mathrm{IN}}$ 的主要因素. 为探讨引水 TP 负荷对 $T P L_{\mathrm{IN}}$ 的影响程度, 对引水期和 非引水期 TP 负荷进行对比, 如图 3(b) 所示. 引水期年际变化较非引水期剧烈, 年均 $T P L_{\mathrm{IN}}$ 为 $102.45 \mathrm{t} / \mathrm{a}$, 占 人库 TP 负荷的 $83 \%$. 进一步分析自产水 TP 负荷, 引水期自产水 TP 负荷年均仅为 $11.54 \mathrm{t} / \mathrm{a}$, 占引水期 $T P L_{\mathrm{IN}}$ 的 $5 \%$, 非引水期为 $20.44 \mathrm{t} / \mathrm{a}$. 从全年角度来看, $T P L_{\mathrm{IN}}$ 的 $74 \%$ 来源于引水, $36 \%$ 来源于自产水. 可见, 本流域 内的自产水携带的 TP 负荷相对较少,外流域引水携带的 TP 负荷是 $T P L_{\mathrm{IN}}$ 的主要来源.
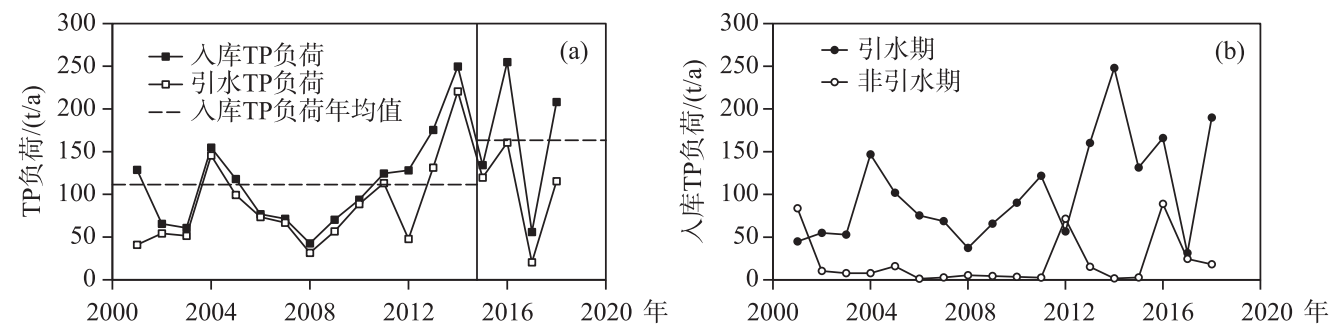

图 $32001-2018$ 年于桥水库人库总磷负荷

Fig.3 Total phosphorus loadings flow into Yuqiao Reservoir ( $\left.T P L_{\mathrm{IN}}\right)$ during 2001-2018

于桥水库引水期一般分为汛前和汛后两个时段, 大部分年份于 4-6 和 9-12 月引水,共持续 5 6 个 月. 结合引水情况分析, 2004、2016 年均为枯水年, 但引水期较短 (不足 4 个月), 短时间高水量导致河床底质 扰动增强 ${ }^{[31]}$, 加剧了枯水年河流中的 TP 浓度, 故导致 TP 负荷较大. 2017 年仅 8 月份引水, 上游潘家口水 库、大黑汀水库采取了清除网箱养鱼等措施, TP 浓度大幅减少, 有效降低了 TP 负荷. 除上述原因造成通水 后年均 TP 负荷仍然较大外, 综合图 2(a) 和图 3(a), 笔者发现人库水量的减少并未使 TP 负荷减少, 人库水

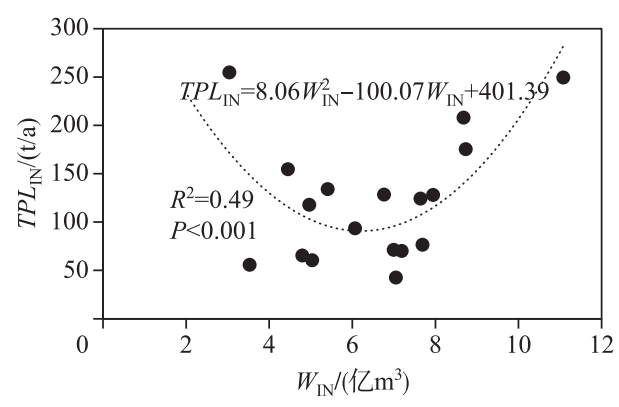

图 4 人库水量与人库总磷负荷关系

Fig.4 Relationship between inflow and total phosphorus loadings
量和 TP 负荷的关系是怎样的?

为进一步研究人库水量与 $T P L_{\mathrm{IN}}$ 的关系, 对二者进行 回归分析, 如图 4 所示, 发现 $T P L_{\mathrm{IN}}$ 随 $W_{\mathrm{IN}}$ 呈先降低后升高 的趋势. 当 $W_{\text {IN }}$ 较小时, 如小于 6 亿 $\mathrm{m}^{3}$, 人库水量对 TP 的 稀释作用较为显著, 随着水量增加人库 TP 负荷减少, 即 外流域引水稀释本流域 TP 负荷的作用较携带 TP 更为突 出; 当 $W_{\mathrm{IN}}$ 大于 6 亿 $\mathrm{m}^{3}$, 引水携带 $\mathrm{TP}$ 负荷造成两者显著正 相关. 同时, 图 4 回答了前述问题, 南水北调通水后年均人 库水量为 5.16 亿 $\mathrm{m}^{3}$, TP 负荷随水量减少而增加. 虽然该 种关系受水库水环境管理措施和年尺度统计数据的影响, 在个别年份具有一定的不确定性, 但整体趋势如上所述.

\section{2 水库磷滞留过程的机制分析}

2.2.1 沉降系数 $a 、 b$ 确定 Larsen 和 Mercier ${ }^{[32]}$ 发现将磷 
沉降模拟为水力停留时间 $\tau$ 的函数 $\sigma=a \tau^{b}$ 时预测 $T P_{\mathrm{L}}$ 与实测 $T P_{\mathrm{L}}$ 拟合度最高. 随后学者们发现总磷损失 率与湖泊水力停留时间的倒数呈正比 ${ }^{[33-34]}$, Brett 和 Benjamin ${ }^{[3]}$ 研究得到 $a 、 b$ 取值决定于具体的湖泊. 为得 到适用于于桥水库的 $a 、 b$ 值, 图 5(a) 绘制了先将 Brett 和 Benjamin 研究结果 $a=1.12 \pm 0.08$ 年 ${ }^{-0.47}, b=-0.53 \pm$ 0.03 代人公式 (3) 计算得到的 $T P_{\mathrm{L}}$ 与实测 $T P_{\mathrm{L}}$ 的对比图, 可以看出预测 $T P_{\mathrm{L}}$ 与实测 $T P_{\mathrm{L}}$ 呈显著线性相关, 然 而, $78 \%$ 的预测值偏向高估. 这是因为当通过 $\tau$ 计算营养物浓度数据时, 长的水力停留时间 ( $>0.4$ 年) 会使 湖泊的预测 TP 浓度倾向于高于实测值, 而当水力停留时间 $<0.04$ 年时预测值低于实测值 ${ }^{[35]}$. 于桥水库的 $\tau$ 历年均值为 2.33 年, 因而预测值较大. 基于 $\sigma=a \tau^{b}$ 的假设, 利用实测值非线性回归得到 $a 、 b$ 取值: $a=$ $2.203, b=-0.641$, 如图 5 (b) 所示. 低估的预测值降至 $44 \% ; R^{2}$ 值为 0.73 , 表明该假设合理; 均方根误差 (RMSE) 从 0.06 降低至 0.03 , 表明预测值更接近实测值, 参数选取合理. 进一步利用该模型计算库区 TP 负 荷滞留量 $R_{\mathrm{p}}$, 并与实测推算值对比, $R^{2}=0.94$ ( 图 $5 \mathrm{c}$ ), 说明模型精度较好.
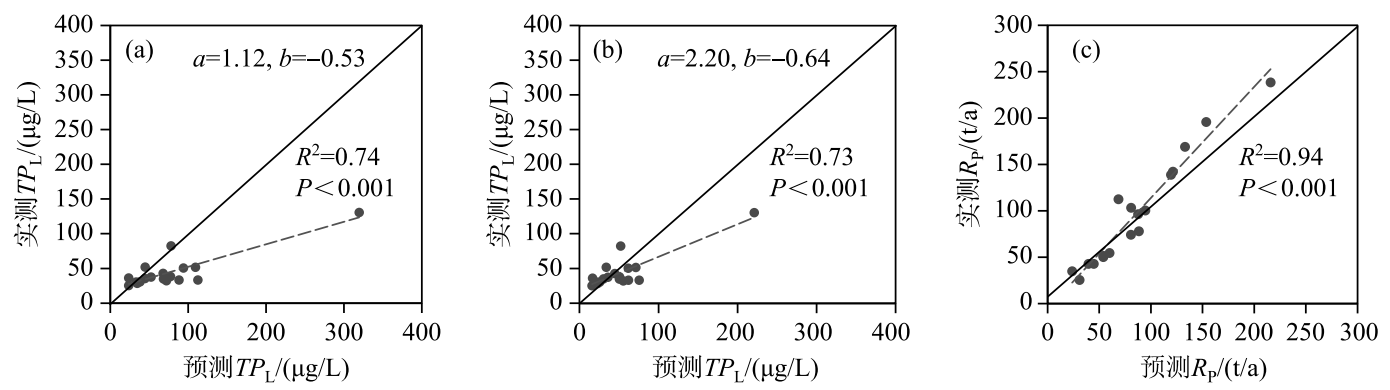

图 5 预测库区总磷浓度与实测库区总磷浓度、预测库区总磷滞留量与实测库区总磷滞留量对比图

Fig.5 Comparison of predicted total phosphorus concentration and observed total phosphorus concentration, and predicted total phosphorus retention and observed total phosphorus retention

2.2.2 库区总磷滞留量 $R_{\mathrm{P}}$ 变化 根据图 6, $R_{\mathrm{P}}$ 总体波动 范围较大. 南水北调通水前, $R_{\mathrm{P}}$ 波动范围为 $30.94 \sim$ $153.59 \mathrm{t} / \mathrm{a}$,年均值 $76.38 \mathrm{t} / \mathrm{a}$,分别于 $2008 、 2014$ 年处于 最小值和最大值. 南水北调通水后, 年际变化剧烈, 2016 年达到历年最大值 $215.86 \mathrm{t} / \mathrm{a}$ 后 2017 年又骤降 为 $44.66 \mathrm{t} / \mathrm{a}$, 年均值上升至 $120.47 \mathrm{t} / \mathrm{a}, R_{\mathrm{P}}$ 增加了 44.09 $\mathrm{t} / \mathrm{a}$. 分析引水期和非引水期 $R_{\mathrm{P}}$, 发现引水期 $R_{\mathrm{P}}$ 随时间 变化情况与年均 $R_{\mathrm{P}}$ 保持高度一致,且基本重合. 图 7 中,引水期 $T P L_{\mathrm{IN}}$ 与 $R_{\mathrm{P}}$ 的线性正相关 $\left(R^{2}=0.91\right)$ 说明引 水期高水平 TP 负荷流人导致更多的磷滞留,即引水期 决定了库区全年 TP 负荷滞留水平. 非引水期 $R_{\mathrm{P}}$ 除 $2001 、 2012 、 2016$ 年外始终维持在较低水平 ( 接近于

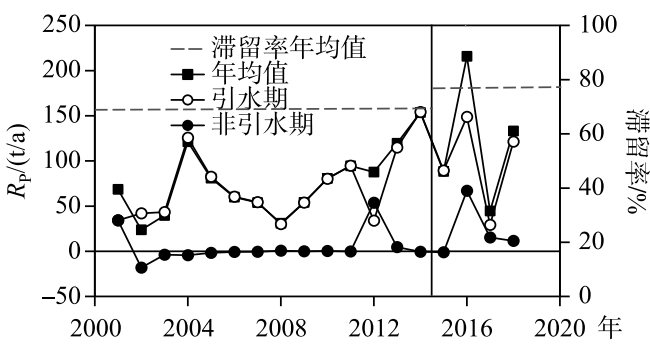

图 $62001-2018$ 年于桥水库 库区总磷滞留量

Fig.6 Total phosphorus retention in Yuqiao Reservoir during 2001-2018 $0)$, 此 3 年汛期 ( $7 、 8$ 月份) 人库水量均较多, 人库 $\mathrm{TP}$ 负荷较大 (图 $2 \mathrm{~b}$ ), 故 $R_{\mathrm{P}}$ 相对较高. 另外, 非引水期 $R_{\mathrm{P}}$ 多年出现负值, 这是因为在非引水期 $T P L_{\mathrm{IN}}$ 显著减少的 情况下, 出库水量受供水需求依然维持在较高水平, 当出库负荷略大于人库负荷, 便出现 $R_{\mathrm{P}}$ 为负值的情况. 2.2.3 水力停留时间 $\tau$ 对磷滞留的影响机制分析 $\tau$ 与 $R_{\mathrm{P}}$ 之间的相关关系如图 8 所示. 通常, 水力停留时间 增加有利于水体自净能力 ${ }^{[36]}$. 从图 8 可以看出, $\tau<0.23$ 年时, $R_{\mathrm{P}}$ 与 $\tau$ 之间存在显著的正相关关系, 该结果 与 Smith 和 Kalff ${ }^{[37]}$ 指出的随水力停留时间增加, 水库对磷的滞留能力增强的结论一致. 但是, 随着 $\tau$ 增加, 正相关性下降, 当考虑全部 $\tau$ 时, $R_{\mathrm{P}}$ 与 $\tau$ 呈负相关. 这是因为人库水量 $W_{\mathrm{IN}}$ 也可能影响磷滞留. $\tau<0.35$ 年时, $W_{\mathrm{IN}}$ 较大, 此时大量 $W_{\mathrm{IN}}$ 携带丰富的 TP 进人水库. 当人库 TP 浓度较高时, 水库底泥主要表现为 “磷汇” ${ }^{[36]}$. 因而较小的 $\tau$ 促进沉积物磷的富集, 导致磷被大量滞留在库中. 有研究表明 ${ }^{[5,38]}$, 具有较小 $\tau$ 的湖泊含有更 


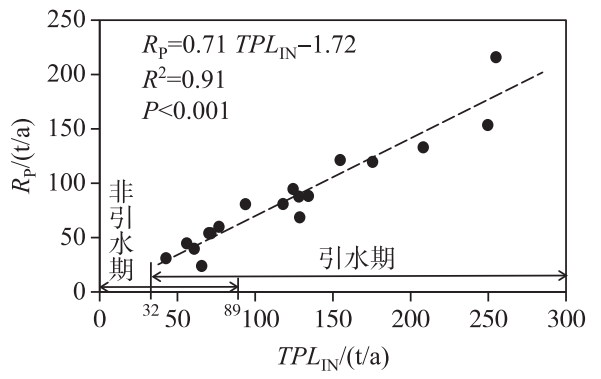

图 7 人库总磷负荷和库区总磷滞留量关系

Fig.7 Relationship of total phosphorus loadings and total phosphorus retention

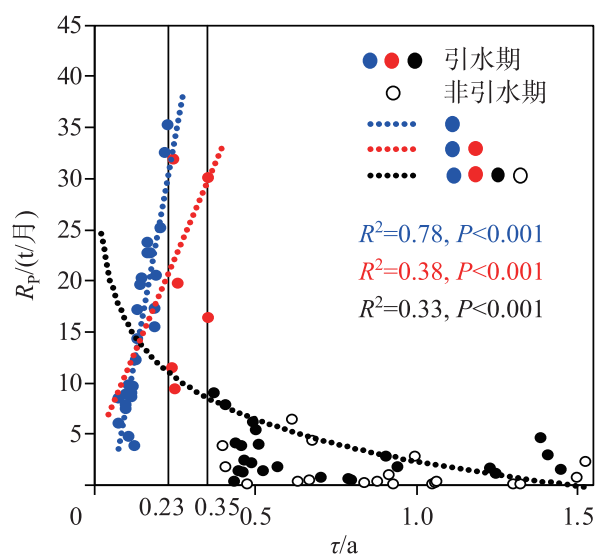

图 8 水力停留时间与库区总磷滞留量的关系

Fig.8 Relationship between hydraulic retention time and total phosphorus retention in the reservoir
多容易与矿物结合的颗粒磷, 而这种颗粒磷更容易沉淀. 所以,当 $\tau<0.35$ 年时, $R_{\mathrm{P}}$ 较大且与 $\tau$ 表现为正相关. 而 $\tau>$ 0.35 年时, $W_{\mathrm{IN}}$ 较小, 人库 $\mathrm{TP}$ 负荷也随之较少, 例如于桥水 库人库负荷均值由临界 $\tau(0.35$ 年) 前 $23.74 \mathrm{t} /$ 月降低为 $6.62 \mathrm{t} /$ 月. 同时, TP 浓度自果河桥至坝前沿程递减, 并且 在水库进口段存在较大的浓度梯度 ${ }^{[23]}$. 进一步分析 $T P L_{\mathrm{OUT}}$ 发现, 出库负荷始终处于较低水平, 临界 $\tau$ 前、后均 值分别为 2.71 和 $2.56 \mathrm{t} /$ 月, 变化不大. 由此可知, $T P L_{\mathrm{IN}}$ 骤 减决定了 $R_{\mathrm{P}}$ 迅速减少.

\section{3 生态水量估算与水库管理建议}

夏军等 ${ }^{[39]}$ 提出生态需水是指维系一定环境功能状况 或目标 (现状、恢复或发展)下客观需求的水资源量. 水利 部海河水利委员会编制的《海河流域水资源保护规划》提 出生态水量原则上采用 Tennant 法 ${ }^{[40]}$ 计算. Tennant 法主 要基于水文资料和年平均径流量百分数来计算生态水量, 根据 Tennant 法推荐表得知多年平均径流量的 $60 \%$ $100 \%$ 为最佳生态水量, 平均径流量的 $200 \%$ 为极限值. 本 文将果河径流量视为于桥水库人库水量 $W_{\mathrm{IN}}, 2001-2018$ 年 $W_{\mathrm{IN}}$ 均值为 6.60 亿 $\mathrm{m}^{3}$, 则于桥水库人库生态水量最佳 范围为 3.96 亿 6.60 亿 $\mathrm{m}^{3}$, 最大不超过 13.20 亿 $\mathrm{m}^{3}$.

由图 6、图 7 可知, $R_{\mathrm{P}}$ 受到 $T P L_{\mathrm{IN}}$ 和 $\tau$ 的综合影响, 且 $R_{\mathrm{P}}$ 在引水期随 $\tau$ 升高有明显增大的趋势, 在引水量较少时 随 $T P L_{\mathrm{IN}}$ 降低而减小. 由此可见,引水期 $R_{\mathrm{P}}$ 主要影响因素 为 $\tau$,非引水期或引水量较少时主要受 $T P L_{\mathrm{IN}}$ 的影响. 同 时, 出库 TP 负荷 $T P L_{\mathrm{OUT}}$ 主要受出库水量的影响. 因此, 针 对不同的人库生态水量, 可以通过调节出库水量达到控制 磷滞留量 $R_{\mathrm{P}}$ 的目的, 从而实现库内 TP 负荷 (内源) 的管 理控制, 即在双水源新情势下防治于桥水库富营养化 趋势.

综合以上分析, 笔者期望在已知生态入库水量情况下, 估算出双水源新情势下的生态出库水量, 以保持 于桥水库处于中贫营养状态. 根据图 5 可知, 南水北调通水前库区 TP 负荷滞留率 $\left(R_{\mathrm{P}} / T P L_{\mathrm{IN}}\right)$ 年均值为 $69 \%$, 通水后上升至 77\% . 库区总磷浓度表明, 2001- 2014 年 $T P_{\mathrm{L}}$ 年均值为 $41.4 \mu \mathrm{g} / \mathrm{L}$, 处于较低水平, $2015-$ 2018 年 $T P_{\mathrm{L}}$ 年均值则升高了一倍. 江雪等 ${ }^{[26]}$ 研究表明, 于桥水库上游径流人库口处从 $1980 \mathrm{~s}$ 起磷的沉积量 迅速增加. 2015 年库区部分区域有富营养化趋势, 沉积物吸附磷增多, 近年来库底淤泥对污染物的沉积能力 已经趋于饱和 ${ }^{[41-42]}$. 滞留于沉积物中的磷越多, 上覆水 TP 浓度越低, 水质越好; 但当磷滞留量过多, 在厌氧 条件下沉积物又会变成 “磷源”, 还原释放 TP 到上覆水中. 为保证沉积物仍为“磷汇”, 本文假设磷滞留保持 在通水前的水平, 即取滞留率为通水前历年平均值计算生态水量. 表 1 给出不同人库水量 $W_{\mathrm{IN}}$ 时, 生态水量 $W_{\mathrm{OUT}}$ 的估算值. 例如当 $W_{\mathrm{IN}}=6$ 亿 $\mathrm{m}^{3}$ 时, 在建立的 $W_{\mathrm{IN}}$ 与 $T P L_{\mathrm{IN}} 、 \tau$ 关系式基础上, 可得到 $T P L_{\mathrm{IN}} 、 \tau$; 根据公式 (3) 由 $\tau$ 得到 $T P_{\mathrm{L}}=54.5 \mu \mathrm{g} / \mathrm{L}$; 取滞留率为 $69 \%$, 则可求出目标 $R_{\mathrm{P}}=60.12 \mathrm{t} / \mathrm{a}$; 再根据 $T P L_{\mathrm{IN}} 、 T P_{\mathrm{L}}$ 与公式 (4) 求得 $W_{\mathrm{OUT}}=5$ 亿 $\mathrm{m}^{3}$, 即于桥水库出库生态水量不小于 5 亿 $\mathrm{m}^{3}$. 同时分析表 1 发现, 当 $W_{\mathrm{IN}}<5$ 亿 $\mathrm{m}^{3}$ 时, $T P_{\mathrm{L}}$ 较高, 不利于于桥水库维持中贫营养状态. 因而, 结合前文 Tennant 法计算得到的生态水量范围, 建议生态人 库水量大于 5 亿 $\mathrm{m}^{3}$, 此时生态出库水量约为人库水量的 $80 \%$.

此外, 2017 年于桥水库前置库建成并试运行, 对降低人库 TP 负荷进一步起到了积极作用. 该前置库位 于水库上游果河, 总占地面积 $22 \mathrm{~km}^{2}$, 工程设施包括坝高 $4 \mathrm{~m}$ 橡胶坝 1 座、渠道、闸涵桥等工程, 种植挺水植 
物 (芦苇和香蒲) 和沉水植物 (蕰草、狐尾藻和微齿眼子菜). 通过前置库单元内的生态系统进行水体净化, 库水面积 $18 \mathrm{~km}^{2}$, 设计年净化规模 5.82 亿 $\mathrm{m}^{3}$, 年削减总磷 $58 \mathrm{t}$ (约占人库负荷的 $48 \%$ ), 从而减少营养负荷 进人于桥水库. 依据前置库的设计总磷消减率, 当 $W_{\mathrm{IN}}$ 为 5 亿 9 亿 $\mathrm{m}^{3}$ 范围时, $T P_{\mathrm{L}}$ 最大值为 $41.8 \mu \mathrm{g} / \mathrm{L}$ $\left(W_{\mathrm{IN}}=9\right.$ 亿 $\left.\mathrm{m}^{3}\right)$, 前置库有效降低了水库 $\mathrm{TP}$ 浓度. 因此, 本文建议的生态水量配合前置库运行将有效保持于 桥水库处于III类水状态.

\section{表 1 年人库水量 $W_{\mathrm{IN}}$ 下生态水量估算 ${ }^{*}$}

Tab.1 Estimation of ecological outflow in different inflow water conditions

\begin{tabular}{cccccccc}
\hline $\begin{array}{c}W_{\mathrm{IN}} / \\
\left(\text { 亿 } \mathrm{m}^{3}\right)\end{array}$ & $\begin{array}{c}T P L_{\mathrm{IN}} / \\
(\mathrm{t} / \mathrm{a})\end{array}$ & $\begin{array}{c}T P_{\mathrm{IN}} / \\
(\mu \mathrm{g} / \mathrm{L})\end{array}$ & $\begin{array}{c}\tau / \\
\mathrm{a}\end{array}$ & $\begin{array}{c}T P_{\mathrm{L}} / \\
(\mu \mathrm{g} / \mathrm{L})\end{array}$ & $\begin{array}{c}R_{\mathrm{P}} / \\
(\mathrm{t} / \mathrm{a})\end{array}$ & $\begin{array}{c}T P L_{\text {OUT }} / \\
(\mathrm{t} / \mathrm{a})\end{array}$ & $\begin{array}{c}W_{\text {OUT }} / \\
\left(\text { 亿 } \mathrm{m}^{3}\right)\end{array}$ \\
\hline 3 & 179.35 & 597.8 & 0.76 & 199.2 & 123.66 & 55.69 & 2.8 \\
4 & 131.61 & 329.0 & 0.64 & 114.5 & 90.75 & 40.87 & 3.6 \\
5 & 100.90 & 201.8 & 0.54 & 73.0 & 69.57 & 31.33 & 4.3 \\
6 & 87.19 & 145.3 & 0.46 & 54.5 & 60.12 & 27.07 & 5.0 \\
7 & 90.50 & 129.3 & 0.39 & 50.2 & 62.40 & 28.10 & 5.6 \\
8 & 110.83 & 138.5 & 0.33 & 55.8 & 76.42 & 34.41 & 6.2 \\
9 & 148.17 & 164.6 & 0.28 & 68.7 & 102.16 & 46.01 & 6.7 \\
10 & 202.53 & 202.5 & 0.23 & 87.7 & 139.64 & 62.89 & 7.2 \\
\hline
\end{tabular}

* $T P L_{\mathrm{IN}}$ 通过图 3 的拟合线计算得出; $\tau$ 的计算公式为: $\tau=-0.44 \ln W_{\mathrm{IN}}+1.2481\left(R^{2}=0.67\right) ; T P_{\mathrm{L}}$ 根据公式 $(3)$ 计算得 出; $R_{\mathrm{P}}=T P L_{\mathrm{IN}} \times 69 \% ; T P L_{\mathrm{OUT}}$ 根据公式 $(4)$ 计算得出.

\section{3 结论}

本文采用 Vollenweider 模型分析了人库水量 $W_{\mathrm{IN}}$ 、人库总磷负荷 $T P L_{\mathrm{IN}}$ 和磷滞留量 $R_{\mathrm{P}}$ 南水北调通水前后 变化规律. 研究表明, 引水结构变化后, 于桥水库人库水量减少, 但并未使 TP 人库负荷减少, 进而磷滞留量 增加. 库区 TP 滞留量增加也将增加水库内源负荷污染风险. 因而, 笔者建议通过调节出人库生态水量以维 持磷滞留在南水北调通水前水平, 防治于桥水库富营养化趋势. 建议人库生态水量大于 5 亿 $\mathrm{m}^{3}$, 出库生态水 量约为人库水量的 $80 \%$, 配合新建前置库工程运行将有效保障水库水源功能.

此外,本文在揭示人库水量和 TP 负荷、水力停留时间和 TP 滞留量机制关系方面做出贡献. 通过 $W_{\mathrm{IN}}$ 与 $T P L_{\mathrm{IN}}$ 相关关系发现, $T P L_{\mathrm{IN}}$ 随 $W_{\mathrm{IN}}$ 呈先降低后升高的趋势, $W_{\mathrm{IN}}$ 较小时, 对 $\mathrm{TP}$ 的稀释作用导致 $T P L_{\mathrm{IN}}$ 降低; $W_{\mathrm{IN}}$ 较大时,引水携带 TP 负荷作用造成两者显著正相关. 探讨水力停留时间 $\tau$ 对 $R_{\mathrm{P}}$ 影响机制发现, 引水期 $\tau(\tau<0.35$ 年 $)$ 和 $R_{\mathrm{P}}$ 之间存在显著的正相关关系, 随着 $\tau$ 增加, 正相关性下降, 引水期 $\tau$ 越长越有利于 $\mathrm{TP}$ 滞 留; 但同时考虑引水期和非引水期 $\tau$ 时, $\tau$ 与 $R_{\mathrm{P}}$ 呈负相关, 非引水期或引水量较少时 $R_{\mathrm{P}}$ 主要受 $T P L_{\mathrm{IN}}$ 的影响, 此时 $T P L_{\mathrm{IN}}$ 随着 $W_{\mathrm{IN}}$ 降低而降低, 导致 $R_{\mathrm{P}}$ 较低. 研究成果为于桥水库运行管理提供了科学依据.

\section{4 参考文献}

[ 1 ] Wang GQ, Ouyang Q, Zhang YD et al eds. World water transfer project. Beijing: Science Press, 2009. [王光谦, 欧阳 琪, 张远东等. 世界调水工程. 北京:科学出版社, 2009.]

[ 2 ] Zhang M, Wang S, Fu B et al. Ecological effects and potential risks of the water diversion project in the Heihe River Basin. Science of the Total Environment, 2018, 619/620: 794-803.

[ 3 ] Brett MT, Benjamin MM. A review and reassessment of lake phosphorus retention and the nutrient loading concept. Freshwater Biology, 2008, 53: 194-211.

[ 4 ] Chang CL, Liu HC. Applying the Back-Propagation Neural Network model and fuzzy classification to evaluate the trophic status of a reservoir system. Environmental Monitoring and Assessment, 2015, 187(9): 567.

[ 5 ] Canfield DE, Bachmann RW. Prediction of total phosphorus concentrations, chlorophyll a, and secchi depths in natural and artificial lakes. Canadian Journal of Fisheries and Aquatic Sciences, 1981, 38(4) : 414-423. 
[ 6 ] Chapra SC, Reckhow KH. Expressing the phosphorus loading concept in probabilistic terms. Journal of the Fisheries Research Board of Canada, 1979, 36(2) : 225-229.

[ 7 ] Reckhow KH. Uncertainty analysis applied to vollenweider phosphorus loading criterion. Journal Water Pollution Control Federation, 1979, 51(8) : 2123-2128.

[ 8 ] Vollenweider RA. Möglichkeiten und Grenzen elementarer Modelle der Stoffbilanz von Seen. Arch Hydrobiol, 1969, 66: 1-36.

[ 9 ] Vollenweider RA. Input-output models with special reference to the phosphorus loading concept in limnology. Schweitz $Z$ Hydrol, 1975, 37: 53-84.

[10] Vollenweider RA. Advances in defining critical loading levels for phosphorus in lake eutrophication. Mem Ist Ital Idrobiol, 1976, 33: 53-83.

[11] Søndergaard M, Bjerring R, Jeppesen E. Persistent internal phosphorus loading during summer in shallow eutrophic lakes. Hydrobiologia, 2013, 710(1): 95-107.

[12] Katsev S. When large lakes respond fast: A parsimonious model for phosphorus dynamics. Journal of Great Lakes Research, 2017, 43(1) : 199-204.

[13] Elliott JA, Ian D, Jones TP. The importance of nutrient source in determining the influence of retention time on phytoplankton: an explorative modelling study of a naturally well-flushed lake. Hydrobiologia, 2009, 627(1) : 129-142.

[14] Soballe DM, Kimmel BL. A large-scale comparison of factors influencing phytoplankton abundance in rivers, lakes, and impoundments. Ecology, 1987, 68: 1943-1954.

[15] Koiv T, Noges T, Laas A. Phosphorus retention as a function of external loading, hydraulic turnover time, area and relative depth in 54 lakes and reservoirs. Hydrobiologia, 2011, 660: 105-115.

[16] Ji ZG, Jin KR. An integrated environmental model for a surface flow constructed wetland: Water quality processes. Ecological Engineering, 2016, 86: 247-261.

[17] Wu P, Qin B, Yu G. Estimates of long-term water total phosphorus ( TP) concentrations in three large shallow lakes in the Yangtze River basin, China. Environmental Science and Pollution Research, 2016, 23(5) : 4938-4948.

[18] Zhang C, Gao XP, Wang LY et al. Modelling the role of epiphyton and water level for submerged macrophyte development with a modified submerged aquatic vegetation model in a shallow reservoir in China. Ecological Engineering, 2015, 81: 123-132.

[19] Zhang C, Liu HA, Gao XP et al. Analysis of the potential impact of climate change on total phosphorus and dissolved oxygen in the bridge reservoir. Environmental Science, 2016, 37(8) : 2932-2939. DOI: 10.13227/j.hjkx.2016.08.014. [张 晨, 刘汉安, 高学平等.气候变化对于桥水库总磷与溶解氧的潜在影响分析. 环境科学, 2016, 37 ( 8): 2932-2939. ]

[20] Zhang C, Liu HA, Gao XP et al. Modeling nutrients, oxygen and critical phosphorus loading in a shallow reservoir in China with a coupled water quality-macrophytes model. Ecological Indicators, 2016, 66: 212-219.

[21] Zhang C, Huang YX, Javed A et al. An ensemble modeling framework to study the effects of climate change on the trophic state of shallow reservoirs. Science of the Total Environment, 2019, 697: 134078. DOI: 10.1016/j.scitotenv.2019.134078.

[22] Chang C, Feng P, Sun DM et al. Prediction of the alga growth in a reservoir based on the stepwise cluster analysis. China Environmental Science, 2015, 35(9) : 2805-2812. [ 常淳, 冯平, 孙冬梅等. 基于逐步聚类分析的水库浮游藻类生长 预测. 中国环境科学, 2015, 35(9): 2805-2812.]

[23] Zhou XS, Ji YL, Kong FQ et al. Primary study on the stratification characteristics of Yuqiao Reservoir based on site monitoring parameters of water quality. Haihe Water Resources, 2015, (2) : 19-21. [ 周绪申, 计亚丽, 孔凡青等. 基于水质 现场监测参数的于桥水库水体分层特征初步研究. 海河水利, 2015, (2) : 19-21.]

[24] Chen YY, Zhang C, Gao XP et al. Long-term variations of water quality in a reservoir in China. Water Science \& Technolo$g y, 2012, \mathbf{6 5}(8): 1454-1460$.

[25] Ge N, Feng P, Sun DM et al. Effects of non-point source pollution of nitrogen and phosphorus on water quality of the Yuqiao Reservoir. Southto-North Water Transfers and Water Science \& Technology, 2015, 13(3): 427-433. [葛宁, 冯平, 孙冬梅等. 库区面源氮、磷污染对于桥水库水质的影响. 南水北调与水利科技, 2015, 13(3): 427-433.]

[26] Jiang X, Shuai L, Yao SC et al. Phosphorus occurrence characteristics and environmental significance of sediments in Yuqiao Reservoir, Tianjin. J Lake Sci, 2018, 30(3) : 50-61. DOI: 10.18307/2018.0305. [江雪, 帅龙, 姚书春等. 天津 于桥水库沉积物磷赋存特征及其环境意义. 湖泊科学, 2018, 30(3) : 50-61.] 
[27] Liu CJ, Yu MH, Zhou CH et al. Effects of water transport on the temporal and spatial variation of water quality in bridge reservoirs. J Lake Sci, 2019, 31(1) : 52-64. DOI: 10.18307/2019.0105. [刘长杰, 余明辉, 周潮晖等. 输水对于桥水 库水质时空变化的影响. 湖泊科学, 2019, 31(1) : 52-64.]

[28] Kronvang B, Hezlar J, Boers P et al. Nutrient Retention Handbook. Software Manual for Euroharp Nutret and Scientific review on nutrient retention, Euroharp report 9-2004, Niva report Sno 4878/2004, Oslo, Norway, 2004:103.

[29] Dillon PJ, Rigler FH. A test of a simple nutrient budget model predicting the phosphorus concentration in lake water. $J$ Fish Res Board Can, 1974, 31: 1771-1778.

[30] Coveney MF, Lowe EF, Battoe LE et al. Response of a eutrophic, shallow subtropical lake to reduced nutrient loading. Freshwater Biology, 2010, 50(10): 1718-1730.

[31] Zhang QQ, Zhou CH, Wang XD et al. Effects of water pollutants from Luanhe-Tianjin water diversion on water environment of Yuqiao reservoir. Water Resources Protection, 2014, (6) : 35-39. [张庆强, 周潮晖, 王旭丹等. 引滦输水污染 物对于桥水库水环境的影响. 水资源保护, 2014, (6) : 35-39.]

[32] Larsen DP, Mercier HT. Phosphorus retention capacity of lakes. Journal of the Fisheries Research Board of Canada, 1976, 33: 1742-1750.

[33] Ahlgren I, Frisk T, Kamp-Nielsen L. Empirical and theoretical models of phosphorus loading, retention, and concentration vs. lake trophic state. Hydrobiologia, 1988, 170: 285-303.

[34] Welch EB, Lindell T. Ecological effects of wastewater: applied limnology andpollutant effects. Journal of the North American Benthological Society, 1992, 12(3): 309.

[35] Bryan MW, Hollister JW, Moore RB et al. Estimating summer nutrient concentrations in northeastern lakes from SPARROW load predictions and modeled lake depth and volume. PLoS ONE, 2013, 8(11) : e81457.

[36] Shen X, Du XZ, Jia DM et al. Analysis of the influence of river input on the phosphorus retention process in Miyun Reservoir. Journal of Environmental Science, 2015, 35(10) : 3114-3120. DOI: 10.13671/j.hjkxxb.2015.0010. [申校, 杜新 忠, 贾东民等. 人库河流输人对密云水库磷滞留过程的影响分析. 环境科学学报, 2015, 35(10): 3114-3120.]

[37] Smith R, Kalff J. Limnology-Inland Water Ecosystems. Journal of the North American Benthological Society, 2002,21 (2) : 346-347.

[38 ] Schindler DW, Fee EJ, Ruszczynski T. Phosphorus input and its consequences for phytoplankton standing crop and production in the Experimental Lakes area and in similar lakes. Journal of the Fisheries Research Board of Canada, 1978, 35 (2) : 190-196.

[39] Xia J, Sun XT, Feng H et al. Challenges in the study of ecological water demand in the western region. China Water Resources, 2003, 5 (5): 57-60. [夏军, 孙雪涛, 丰华丽等. 西部地区生态需水问题研究面临的挑战. 中国水利, $2003,5(5): 57-60$. $]$

[40] Tennant DL. Instream flow regimens for fish, wildlife, recreation and related environmental resources. Fisheries, 1976, 1 (4) : 6-10.

[41] Zhang S, An W, Li X. Research on phosphorus loads and characteristics of adsorption and release in surface sediments of Nanyang Lake and Weishan Lake in China. Environmental Monitoring \& Assessment, 2015, 187(1) : 1-7.

[42] Cheng Y, Lai XJ. Numerical simulation of the influence of ecological dredging on the water quality of Yuqiao Reservoir. Journal of Water Resources and Water Engineering, 2019, 30(3) : 58-65. [程扬, 赖锡军. 生态清淤对于桥水库水质影 响的数值模拟. 水资源与水工程学报, $2019, \mathbf{3 0}(3)$ : 58-65.] 